\title{
Research on the Presentation Methods of Chinese Painting Based on Digital Media Technology
}

\author{
$\mathrm{Xi} \mathrm{Li}$ \\ School of Art \\ Nantong University \\ Nantong, China 226007
}

\author{
Yaohua $\mathrm{Wu}$ \\ School of Art \\ Nantong University \\ Nantong, China 226007
}

\begin{abstract}
With the help of digital media technology, the presentation methods of Chinese painting will be more and more modernized. On the basis of maintaining traditional flat and static presentation methods, and the openness, freedom and humanization of digital media technology, it can greatly enrich the appreciation effect of Chinese painting. It is conducive to the spread of Chinese painting. Also, it is conducive to the innovation of Chinese painting.
\end{abstract}

Keywords—digital media technology; Chinese painting; presentation methods

\section{INTRODUCTION}

With the continuous development and maturity of digital media technology, the presentation method of Chinese painting has undergone earth-shaking changes. The traditional and intuitive presentation method has its own unique superiority. Due to the accelerated pace of people's life and the continuous improvement of people's aesthetic methods, as well as the constant pursuit of the spiritual world, the traditional face-to-face presentation has not been able to spread and share quickly and widely among the public. The presentation method of Chinese painting under digital media technology is characterized by openness, freedom and humanity. These not only promote the inheritance and development of Chinese painting, but also greatly promote the Chinese traditional culture to the international stage.

\section{THE OPENNESS OF PRESENTATION METHOD OF}

\section{Chinese Painting Under Digital Media Technology}

Art should not belong to or be monopolized in the aesthetic vision of some people because of stratum, the richness or poverty. In the era of digital media technology, it is extremely simple to appreciate art. The public can browse online through the Internet or mobile app, or go to the art exhibition to conduct on-the-spot visits. They also can interact and communicate with the others. The core content of this process from monopoly to popularization is the openness of digital media technology, and the core technology is the strong reproducibility of digital media technology. This has led to the reduction in the cost of art communication. Then, the public could appreciate the art.

\section{A. The Opening of Cultural Concepts: the Transition from Elite Art to Mass Culture}

In "Famous Paintings of the Past Dynasties", Zhang Yanyuan wrote something about the paintings. "There is nothing that humble man can be done." In his view, painting is an elegant thing. It is the special thing that only people of the aristocratic class or elites can do it. People in general social status can't engage in such profession. This skills and the elite temperament of Chinese painting are special product of Chinese feudal society and traditional culture. On the one hand, it has certain spiritual connotation. On the other hand, it hinders the general public's appreciation and intervention of Chinese painting. In the digital media era, this situation has changed. Today, with the popularity of the Internet, the general public can search for the artworks they want to watch at any time on their mobile phones. And those painting theories in the past that only literati and officialdom were accessible to, and the artworks that only the royalties could be eligible for collection, can be easily downloaded in this era with just one click.

\section{B. The Opening of the Aesthetic Approach: the Transition from Upper-class People to the Ordinary Civilians}

The presentation method of traditional Chinese painting is a non-popular presentation method, and its content is also non-popular. In the feudal period, it was impossible to learn the special skills of Chinese painting without the master. However, the literati and officialdom or the nobility would often master this skill. They evaluated the artworks and the artists with their own standards and professional scales. At the same time, it would maintain a kind of awe-inspiring inheritance relationship between the master and the apprentice. It is easy to understand and approach to the content of the communication on the surface. However, in fact, it is inscrutable and difficult to understand. Therefore, in the long history, the development of the innovation and diversification of Chinese painting has been limited. Today, with the popularity of digital media technology, the popularity of art have given the opportunity to ordinary people who want to learn art and want to learn Chinese painting. Also, it would make the art take off the noble and gorgeous coat and return to the true plain nature. As the saying goes, "Difference in profession makes one feel worlds apart." The barrier among the industries is difficult to pass. 
There is a saying when admiring Chinese paintings, "the experts look at the method, and the layman looks at the excitement." In fact, the reason why the industry is difficult to communicate is that there is no scale to make the transformation among them. And digital media technology first becomes such a common language that is easy to master and communicate. At the same time, digital media technology has greatly improved the public's aesthetic ability. People can reach out to more artworks than ever before through digital presentation method. Facing many art works, whether it is the handed-down works of thousands of years or the new ink of modern times, everyone's aesthetic feeling is different. Through the mass media, they have their own specific aesthetic consciousness. And it is no longer to rely on the ideas of experts.

\section{The Opening of Recreation: the Transformation from Individual Monopoly to Multi-person Derivatization}

In the context of current digital media technology, Chinese painting art can be as strong as a software or program. As long as there is an original work, the new version can be derived. Only those works with sufficient derivation ability are the true success of Chinese painting. Only in this way can the artistic creation of Chinese painting meet the "massive" needs of digital media communication, and can truly realize the integration between the creation of beauty and the examination of beauty. The so-called recipient is the creator and completely deconstructs the professional monopoly of artistic creation. Some people who are eager to step into the art field but lack basic skills can use their computers to collage or transfer existing elements to express their creative intent. They obtain the aesthetic inspiration and creative impulse from appreciating the existing artworks. And they would use it as a blueprint for the recreation and copying. Then, they could develop new artworks in a deductive way. People can more or less see many similarities in such artworks. However, it represents a new product, a new perspective and a new feeling.

\section{The Freedom of Presentation Method of Chinese Painting Under Digital Media TEChNOLOGY}

The traditional Chinese paintings are generally presented in physical form, and people need to go to the scene to watch them. In this case, the viewers are easily limited by time and space. At the same time, a large number of Chinese paintings are presented in a museum-based manner, and the medium presented is too monotonous. It is greatly influenced by the promotion and dissemination of Chinese painting. The use of digital media technology can easily solve this series of problems. Because of the virtual nature of digital media technology, it has surpassed any forms of the present media. People can flip through and look up Chinese paintings on their mobile phones at home. The presentation method would be younger and more diverse. Combining with the presentation of new media, China's traditional Chinese painting skills have given birth to new vitality. The dependence of digital media art on technology is different from the dependence of traditional art on creative materials. The creation of traditional painting art relies on mineral pigments such as brushes, canvases and pigments. And viewers' appreciation of works does not depend on these material substances. Therefore, many elements of Chinese paintings can be presented in more visually striking media such as movies and games (As shown in "Fig. 1"), and then they are loved by young people. The rapid development of the Internet, especially broadband Internet, has made remote transmission multimedia art works be the reality. Artists can easily edit digital images with the help of self-media, and the artist will present and publish the completed artworks through the network. At the same time, the artist can explain his work on the live broadcasting and quickly introduce the artwork to art lovers all over the world without troubles in presentation method.

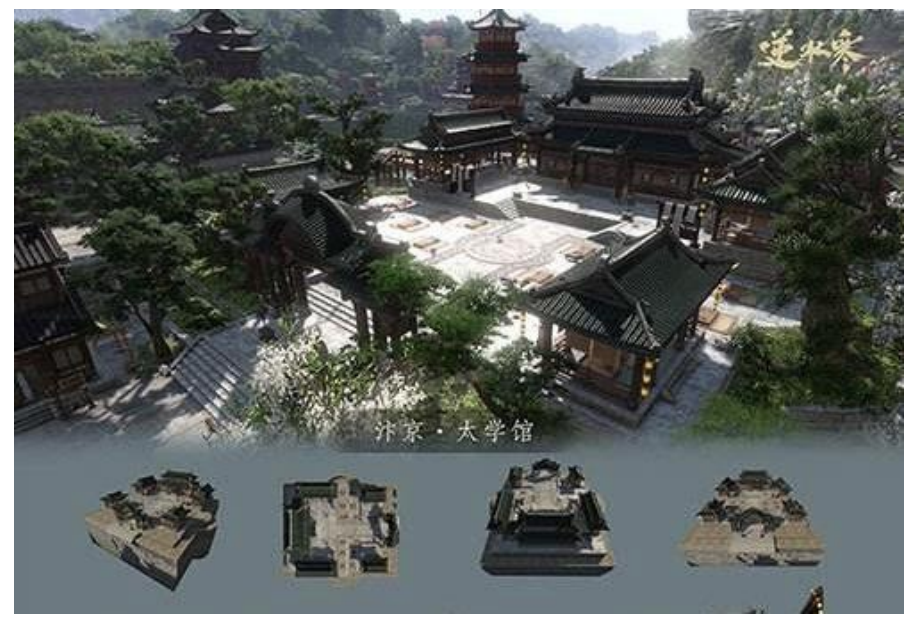

Fig. 1. Game scene.

\section{A. Freedom of Presentation Time and Space}

In traditional exhibition of museum, they would use intuitive presentation method. Usually, the artworks would be presented for the audience in a hanging manner. In this case, the presentation method would be limited by the time and space. In terms of time, museum exhibitions have their own time for opening and closing, and people can't visit at 
any time. And the number of visits is large. The viewers are easy to be limited by time. Then, they would quickly browse through the scenes. This way of appreciation greatly reduces the browsing experience. Because of its virtualization and digital features, digital media technology can spread in many ways, breaking the limits of traditional display technology. For example, the Palace Museum put a high-definition digital version of its collection on the Internet (As shown in "Fig. 2"). People can watch and browse at home. For students of professional appreciation, it is possible to carry out detailed analysis of Chinese paintings, which is not only fast and convenient, but also has many guarantees for its authenticity. At the same time, the search function is provided on the website. The viewer can quickly and purposely find the target work that he needs. And it would provide better viewing experience.

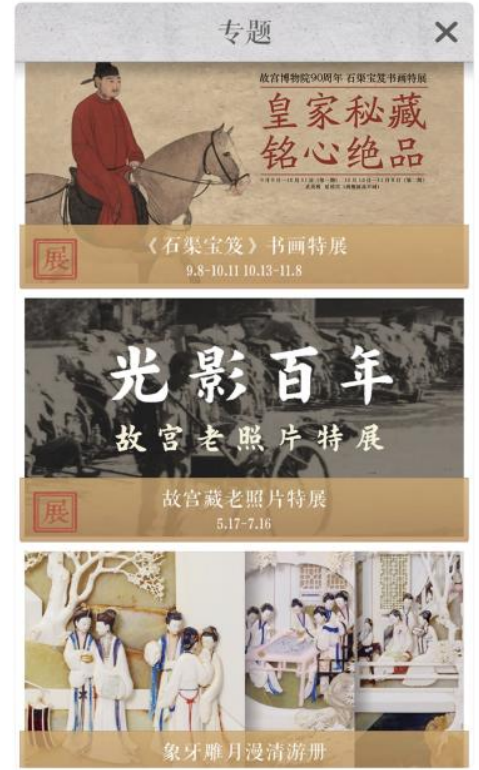

Fig. 2. The network effect.

\section{B. The Freedom of Presentation Media}

Using digital media technology, the monotonous information in the traditional Chinese painting display technology can be transformed into a rich presentation form such as video and animation, which enhances the interest of the display and the acceptance of the audience. Using digital media presentation can increase the viewer's participation and display interactivity. Digital technology enables the unrecoverable abstract historical scene to be visualized in front of contemporary people. At the end of 2005, two top animation production companies in China were invited to make the large-scale documentary "The Imperial Palace". For Chinese documentaries, the producers used computer models to create historical scene and historical picture. Among them, it would use the combination of $3 \mathrm{D}$ production and $2 \mathrm{D}$ production. There is a group of Chinese paintings. Using digital animation, this Chinese painting is moving. In the picture, the water is flexible, the clouds are floating, and the birds are flying in the mountains. The blueprint of this scene is the court painting of the Ming Dynasty painter. It has the aesthetic style and artistic characteristics of the typical Chinese court painting. Combining these paintings with computer animation technology, the character, the cloud and the flowing water in the picture are live. The unique visual effects make this group of the images in the activity have remarkable Chinese traditional painting temperament and typical court characteristics. The color and composition also show the inheritance of the history spanning hundreds of years. From the three-dimensional perspectives, in this documentary, the creators use digital media technology to create things and landscapes that have existed in history but now have no trace. And the characters in the twodimensional paintings created by the ancients are live. Today, the digital media art seems to have given life to the history that has passed away. And history has risen in the eyes of people. This abstract history restores the figurative digital media art, which enables the viewers to come out of the ancient paintings, and to come out of the history of abstract symbol combinations in the texts. The viewers truly touch the real situation of that year with their own eyes.

\section{The Freedom of Presentation Content}

Digital technology can generate any things that people can imagine. It means that people can also show things that are invisible to be seen by the human eye. And it would magnify the objects being rendered. No matter how small the object is, digital technology can magnify it. The invisible world would be magnified. Many small details of Chinese painting are difficult to be clearly presented to the viewer during the traditional visual display process. And the digital technology brings the magnification function. No matter how small things are, they can be presented (As shown in "Fig. 3 "). And the size of the presentation is different. The degree of magnification of the object is arbitrary. The public can see the beauty of the details of Chinese painting according to their own needs. The digital generation function can also display things that are too large to be captured by the human eye. And the objects to be presented are reduced. No matter how large the object is, digital technology can reduce it arbitrarily and narrow the world beyond the human eye. It can be covered by the human eye. Chinese painting pays attention to layout. Therefore, the author can't draw all the content he sees. Using digital media technology, artists can use this as a cornerstone to restore an entire city at that time according to the buildings and characters depicted in Chinese paintings. The viewer can better understand the society at that time and the characteristics of the times. 


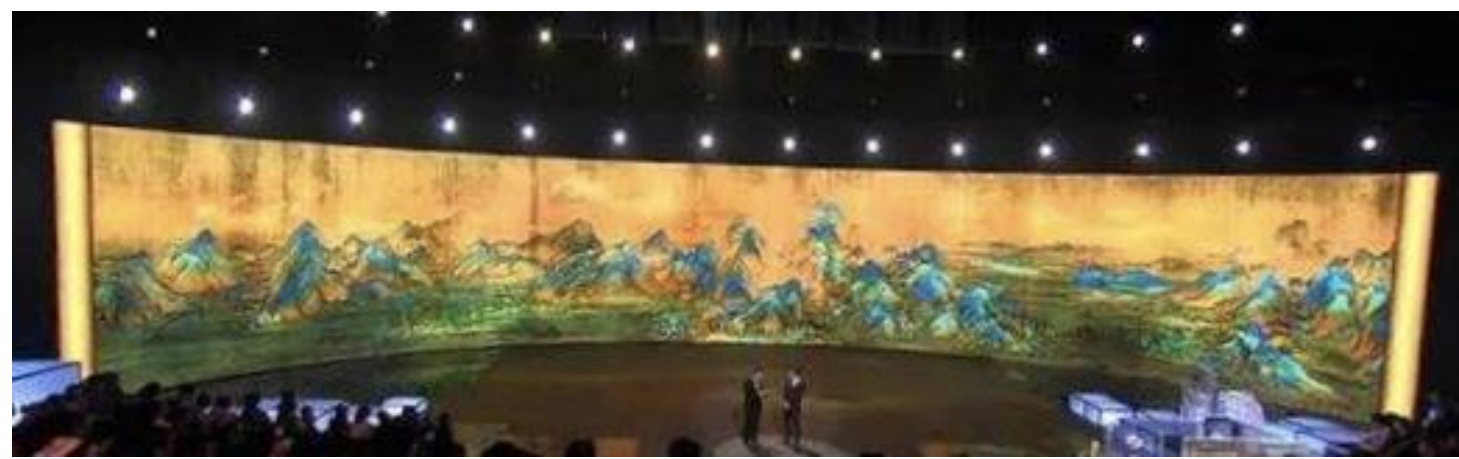

Fig. 3. The screen rendering.

\section{The Humanization OF PRESENTATION METHOD OF Chinese Painting Under Digital Media TeChNOlOGY}

In recent years, with the continuous expansion of the application of digital media technology, people have gradually changed the habit of receiving information. And it is more and more inclined to accept information through images, sounds, animations, etc. People would pursue the interaction effect of communicating with the information transmitter. The presentation method of traditional Chinese paintings is one-way and static. And it is slightly insufficient in terms of interactivity. For the younger generation, especially the children, there are certain limitations in the process of spreading the traditional culture of Chinese painting.

\section{A. Interestingness in Interaction and Evaluation}

Art is the artist's recreation of the real world, expressing some basic ideas about humans and society that can be shared with others. Therefore, the audience's experience of art works is a very important part. In the process of presentation, through the effective interaction with the viewer, the fun of Chinese painting appreciation increases.

\section{B. The Simplicity of Search}

Traditional display technology is limited by the size of the information on the display board, and information that cannot be displayed in large quantities can be realized by digital media technology. The relevant information of the browsing paintings required by the Chinese Painting Art Exhibition would be input into the computer to form an information database (As shown in "Fig. 4"). And an information inquiry device is deployed in the exhibition hall. The viewer can make the search according to the required information. The query content accommodates a large amount of background knowledge and can be efficiently provided through effective interaction design. It not only greatly saves the exhibition space, but also avoids the clutter caused by a large amount of information, and helps the audience understand the Chinese painting art more comprehensively.

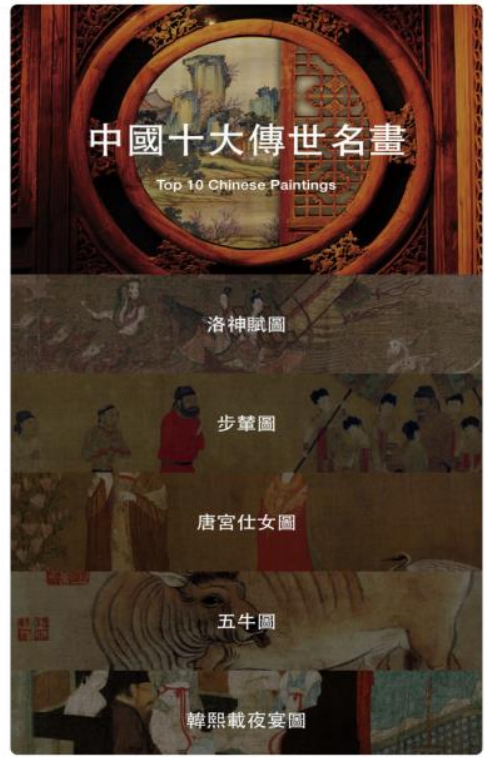

Fig. 4. The data application.

\section{CONCLUSION}

China is a big country with a long history of art and rich artistic elements. Grasping new technologies and climbing the new high point of artistic development, the organic combination of digital media technology and Chinese painting art has gradually become a trend. However, it is not to abandon the traditional presentation method. The traditional presentation method has its indispensable advantages. And the widespread use of digital media technology will also weaken the artistic conception of Chinese painting. Therefore, the communication between digital media technology and Chinese painting art makes the two complement each other. The complementary advantages are conducive to the better presentation and dissemination of Chinese painting. It is the direction we need to study in the future.

\section{REFERENCES}

[1] Li Sida. History of Digital Media Art [M]. Beijing: Tsinghua University Press, 2008. 李四达.数字媒体艺术史 $[\mathrm{M}]$. 北京:清华大 学出版社,2008. 
[2] Wu Qi. Analysis of Digital Media Works [M]. Beijing: Beijing University of Posts and Telecommunications Press, 2008. 吴起.数字 媒体作品剖析[M].北京: 北京邮电大学出版社,2008.

[3] Wang Daiming. Development of Digital Media and Art [M]. Sichuan: Bayu Shushe, 2007. 汪代明.数字媒体与艺术发展 [M].四川:巴蜀书 社,2007.

[4] Li Sida. Introduction to Digital Media Art [M]. Beijing: Tsinghua University Press, 2006. 李四达.数字媒体艺术概论 [M]. 北京: 清华 大学出版社,2006.

[5] Wang Limin. Digitalization and Modern Art [M]. Beijing: China Radio and Television Publishing House, 2006. 王利敏.数字化与现 代艺术 $[\mathrm{M}]$. 北京:中国广播电视出版社, 2006 .

[6] Liao Xiangzhong. Digital Art Theory [M]. Beijing: China Radio and Television Publishing House, 2006. 廖祥忠. 数字艺术论 $[\mathrm{M}]$. 北京: 中国广播电视出版社, 2006.

[7] Zhang Yanxiang. New Media Art [M]. Beijing: Science Press, 2005. 张燕翔.新媒体艺术 $[\mathrm{M}]$. 北京:科学出版社, 2005 .

[8] Cheng Yong. Chinese Elements [M]. Shanghai: Oriental Publishing Center, 2009. 程庸.中国元素[M].上海:东方出版中心,2009.

[9] Yu Hong. Introduction to Aesthetic Culture [M]. Beijing: Higher Education Press, 2006. 余虹. 审美文化导论[M]. 北京: 高等教育出版 社,2006.

[10] Zong Baihua. Aesthetic Walking [M]. Shanghai: Shanghai People's Publishing House, 2007. 宗白华.美学散步 $[\mathrm{M}]$. 上海:上海人民出版 社,2007.

[11] Li Zehou. The History of Beauty [M]. Guilin: Guangxi Normal University Press, 2001. 李泽厚. 美的历程[M]. 桂林:广西师范大学 出版社,2001.

[12] Li Zehou, Liu Gangji. History of Chinese Aesthetics [M]. Hefei: Anhui Literature and Art Publishing House, 1999. 李泽厚, 刘纲纪.中 国美学史[M].合肥:安徽文艺出版社,1999.

[13] Xu Fuguan. Chinese Art Spirit [M]. Shanghai: East China Normal University Press, 2001. 徐复观.中国艺术精神[M].上海:华东师范 大学出版社,2001.

[14] Lai Xianzong. Artistic Conception and Hermeneutics [M]. Peking University Press, 2009. 赖贤宗. 意境美学与诠释学 $[\mathrm{M}]$. 北京大学出 版社,2009.

[15] Ye Lang. Aesthetic Principles [M]. Peking University Press, 2009. 叶朗.美学原理[M].北京大学出版社,2009.

[16] Zhu Liangzhi. The 15th Lecture of Chinese Aesthetics [M]. Peking University Press, 2006. 朱良志. 中国美学十五讲[M]. 北京大学出版 社, 2006. 